\title{
Preparation and Evaluation of a Profile Control Agent Base on Waste Drilling Fluid
}

\author{
Xiaoping Qin, Haiwei Lu, Yilin Li, Tong Peng, Lijie Xing, Haixi Xue, and Jing Xu \\ Drilling and Production Technology Research Institute, PetroChina Jidong Oilfield Company, Tangshan 063004, China \\ Correspondence should be addressed to Xiaoping Qin; 948801727@qq.com
}

Received 22 November 2016; Revised 13 February 2017; Accepted 26 February 2017; Published 12 March 2017

Academic Editor: Nicolas Roche

Copyright (C) 2017 Xiaoping Qin et al. This is an open access article distributed under the Creative Commons Attribution License, which permits unrestricted use, distribution, and reproduction in any medium, provided the original work is properly cited.

\begin{abstract}
The waste drilling fluid was treated by a flocculant and a $\mathrm{pH}$ regulator. And a novel profile control agent base on waste drilling fluid (PCAWDF) was prepared using polymer, formaldehyde, resorcinol, and thiourea as raw materials under mild conditions. PCAWDF was characterized by infrared (IR) spectroscopy and scanning electron microscope (SEM). Compared with the profile control agent prepared by the recirculated water (PCARW), PCAWDF exhibited comparable or better stability, salt resistance, and viscoelasticity. The results of parallel core plugging experiments showed that the profile improvement capability of PCAWDF was stronger than that of PCARW (for $3000 \mathrm{mg} / \mathrm{L}$ : $84.6 \%$ versus $83.1 \%$; for $5000 \mathrm{mg} / \mathrm{L}$ : $91.8 \%$ versus $90.2 \%$ ). The main performance indexes of PCAWDF could meet the need of profile control for the water injection wells. The method could solve the problem of waste drilling fluid treatment in an economic and environmental way.
\end{abstract}

\section{Introduction}

Waste drilling fluid contains a large number of additives, treatment agents, and other chemical agents, so random discharge of untreated waste drilling fluid will cause serious damage to the ecological environment [1-3]. However, achieving standard emissions requires a high cost of treatment [4-6]. Therefore, in order to reduce disposal cost of waste drilling fluid and protect the ecological environment, waste drilling fluid treatment technology needs to be further studied[7-10].

At present, the drilling fluid systems used in China's oil fields are usually polymer drilling fluid, polysulfonate drilling fluid, $\mathrm{KCl}$ film-forming drilling fluid, $\mathrm{KCl}$ antihigh temperature drilling fluid, and so on. Among them, polysulfonate drilling fluid is the most widely used one. The curing with drilling treatment technology is usually adopted in the waste polysulfonate drilling fluid, which is achieved by adding cement, lime, and fly ash into the waste drilling fluid [11-14]. Chemical substances in the treatment products will pollute the ground water and air [15-18]. In addition, this method greatly increases the processing cost of waste drilling fluid (around 10 dollars/square meter).
Profile modification in water injection wells can improve the water injection profile, thereby increasing the swept volume of injected water. The main profile control agents are cement profile control agent, resin profile control agent, inorganic salt precipitation type profile control agent, gel profile control agent, and so forth. Gel profile control agent has many advantages, such as easy injection, low cost, and good sealing ability, so it is widely used in water injection wells profile control.

Keeping in mind all above points, herein, a novel gel profile control agent base on waste drilling fluid was prepared. This method not only solves the problem of high treatment cost of waste drilling fluid but also provides a water source for profile control of water injection well. After all, surface water resources are limited.

\section{Experimental}

2.1. Chemicals and Reagents. Aluminum sulfate (AR), sodium hydroxide (AR), formaldehyde (mass concentration $37 \%$ water solution), resorcinol (AR), thiourea (AR), sodium chloride $(\mathrm{NaCl}, \mathrm{AR})$, calcium chloride anhydrous $\left(\mathrm{CaCl}_{2}\right.$, $\mathrm{AR})$, magnesium chloride hexahydrate $\left(\mathrm{MgCl}_{2} \cdot 6 \mathrm{H}_{2} \mathrm{O}, \mathrm{AR}\right)$, 
TABLE 1: The reagent dosage of polymer solutions and profile control agents.

\begin{tabular}{|c|c|c|c|c|c|}
\hline Preparation water & $\begin{array}{l}\text { Polymer } \\
\mathrm{mg} / \mathrm{L}\end{array}$ & $\begin{array}{c}\text { Formaldehyde } \\
\mathrm{mg} / \mathrm{L}\end{array}$ & $\begin{array}{c}\text { Resorcinol } \\
\mathrm{mg} / \mathrm{L}\end{array}$ & $\begin{array}{l}\text { Thiourea } \\
\mathrm{mg} / \mathrm{L}\end{array}$ & Code \\
\hline TWDF & 3000 & 1 & 1 & 1 & 3000-TWDF \\
\hline TWDF & 5000 & l & l & I & 5000-TWDF \\
\hline Recirculated water & 3000 & l & l & I & 3000-RW \\
\hline Recirculated water & 5000 & l & l & l & 5000-RW \\
\hline TWDF & 3000 & 2000 & 600 & 100 & 3000-PCAWDF \\
\hline TWDF & 5000 & 3000 & 1000 & 120 & 5000-PCAWDF \\
\hline Recirculated water & 3000 & 2000 & 600 & 100 & 3000-PCARW \\
\hline Recirculated water & 5000 & 3000 & 1000 & 120 & 5000-PCARW \\
\hline
\end{tabular}

TABLE 2: TDS and chemical composition of the formation water and the recirculated water.

\begin{tabular}{lccccrrr}
\hline Items & $\mathrm{Na}^{+}+\mathrm{K}^{+}$ & $\mathrm{Ca}^{2+}$ & $\mathrm{Mg}^{2+}$ & $\mathrm{SO}_{4}^{2-}$ & $\mathrm{Cl}^{-}$ & $\mathrm{HCO}_{3}^{-}$ & $\mathrm{TDS}^{-}$ \\
\hline Content of the recirculated water $(\mathrm{mg} / \mathrm{L})$ & 2093.3 & 73.8 & 41.2 & 94.5 & 3224.5 & 417.6 & 5944.9 \\
Content of the formation water $(\mathrm{mg} / \mathrm{L})$ & 3071.6 & 131.1 & 53.6 & 124.9 & 4580.7 & 573.2 & 8535.1 \\
\hline
\end{tabular}

potassium chloride $(\mathrm{KCl}, \mathrm{AR})$, sodium sulfate $\left(\mathrm{Na}_{2} \mathrm{SO}_{4}, \mathrm{AR}\right)$, and sodium bicarbonate $\left(\mathrm{NaHCO}_{3}, \mathrm{AR}\right)$ were purchased from Chengdu Kelong Chemical Reagent Factory (Sichuan, China). All chemicals and reagents were used as received without any further purification. Partially hydrolyzed polyacrylamide (HPAM, degree of hydrolysis: $25 \%$, viscosity molecular weight: $22 \times 10^{6}$ ) was purchased from Daqing Lianhua Technology Co., Ltd.

2.2. Treatment of Waste Drilling Fluid. The waste drilling fluid was taken from X88 well, and the polymer sulfonate drilling fluid was used in this well. This drilling fluid was composed of a base slurry, a partially hydrolyzed polyacrylamide, a partially hydrolyzed polyacrylamide ammonium salt, a liquid lubricant, an ultralow permeability treatment agent, and a $\mathrm{pH}$ regulator. Solid fraction in the waste drilling fluid was removed with high frequency sieve. The flocculant aluminum sulfate was added to remove the colloidal particles and suspended matter in the liquid phase. Then sodium hydroxide was added to regulate the $\mathrm{pH}$ of solution as $7-8$, and the treated waste drilling fluid (TWDF) was obtained.

2.3. Preparation of Profile Control Agent. Profile control agents were prepared using preparation water (TWDF or recirculated water), HPAM, formaldehyde, resorcinol, and thiourea at room temperature. The dosage of each agent is shown in Table 1 . The polymer was added to the preparation water, and the polymer was stirred until being completely dissolved. Then formaldehyde, resorcinol, and thiourea were added to the polymer solution, and the mixture was stirred for $20 \mathrm{~min}$. Finally, these profile control agents were obtained and loaded into sealed bottles.

2.4. Stability. Different concentrations of profile control agents were prepared by the given methods and loaded into sealed bottles. These profile control agents were put into a constant temperature box $\left(65^{\circ} \mathrm{C}\right)$. Every 10 days, the apparent viscosity of these profile control agents was tested using Brookfiled DV3T viscometer at $65^{\circ} \mathrm{C}$.

2.5. Salt Resistance. The salt resistance performance was studied by increasing $\mathrm{NaCl}$ concentration in the recirculated water or TWDF, and then profile control agents prepared using these waters were aged $72 \mathrm{~h}$ at $65^{\circ} \mathrm{C}$. The apparent viscosity of these profile control agents was measured via Brookfiled DV3T viscometer at $65^{\circ} \mathrm{C}$.

2.6. Viscoelasticity. Profile control agents were formulated with the preparation water and placed for $72 \mathrm{~h}$ at $65^{\circ} \mathrm{C}$. Viscoelasticity measurements of these profile control agents were conducted on an Anton Paar MCR102 Rheometer. The test system was plate, and the rotor was PP50 at $65^{\circ} \mathrm{C}$. The range of scanning frequency $(f)$ was $0.5-10 \mathrm{~Hz}$, and the stress was $0.5 \mathrm{~Pa}$ by using the same test system and rotor in viscoelasticity measurements.

2.7. Parallel Core Plugging Experiment. Sandstone cores were used to study the profile improvement ability of these profile control agents. Total dissolved solids (TDS) and chemical composition of the formation water and the recirculated water are listed in Table 2.

According to the flow chart (Figure 1), the experimental devices were connected. If not otherwise noted, all experiments were carried out at $65^{\circ} \mathrm{C}$. The cores were placed into the Hassler core holders with 1.0 MPa backpressure and 3.0 $\mathrm{MPa}$ confining pressure. These cores were saturated with the formation water at $0.5 \mathrm{~mL} / \mathrm{min}$, and then $0.5 \mathrm{PV}$ (pore volume) profile control agent was injected into the cores. After aging for $72 \mathrm{~h}$, the recirculated water was injected into the cores at $0.5 \mathrm{~mL} / \mathrm{min}$ until the flow rate was stable.

The profile improvement rate of profile control agent is calculated with the following equation:

$$
f=\frac{Q_{\mathrm{hb}} / Q_{\mathrm{lb}}-Q_{\mathrm{ha}} / Q_{\mathrm{la}}}{Q_{\mathrm{hb}} / Q_{\mathrm{lb}}},
$$




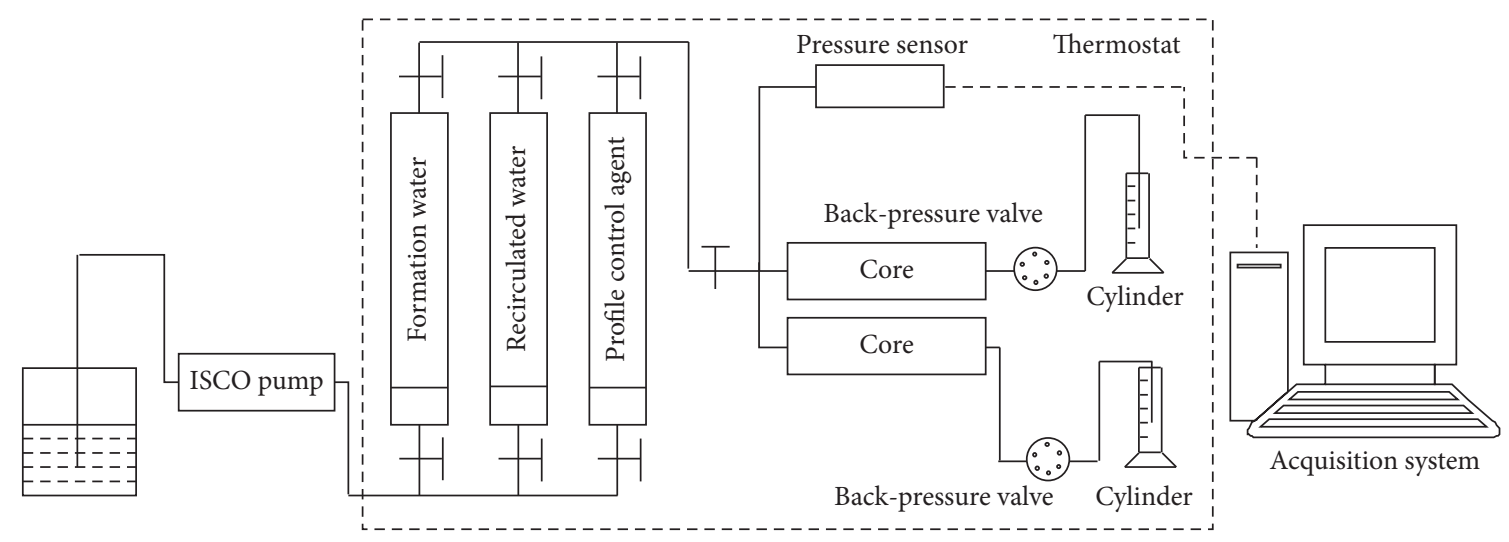

FIGURE 1: Flow chart of the parallel core plugging tests.

where $f$ is the profile improvement rate of profile control agent, \%; $Q_{\mathrm{hb}}$ is the percentage of water absorption before high permeability core profile control, $\%$; $Q_{\text {ha }}$ is the percentage of water absorption after high permeability core profile control, \%; $Q_{\mathrm{lb}}$ is the percentage of water absorption before low permeability core profile control, \%; and $Q_{\mathrm{la}}$ is the percentage of water absorption after low permeability core profile control, \%.

\section{Results and Discussion}

3.1. Viscosity of Polymer Solution Prepared Using TWDF. As shown in Figure 2, the viscosity difference of these polymer solutions prepared with TWDF or recirculated water was very small under the same conditions. Viscosity comparison results showed that the flocculant and $\mathrm{pH}$ modifier could effectively improve the water quality of the waste drilling fluid. In this way, the polymer solution could be prepared with TWDF instead of the recirculated water.

3.2. IR Spectra Analysis of Profile Control Agents. The structures of PCAWDF and HPAM were confirmed by IR spectra as illustrated in Figure 3. The PCAWDF prepared using HPAM, formaldehyde, and resorcinol was confirmed by strong absorption at $3438.5 \mathrm{~cm}^{-1}$ (-NH stretching vibration), $2938.7 \mathrm{~cm}^{-1}$ (- $\mathrm{CH}_{2}$ stretching vibration), $1672.2 \mathrm{~cm}^{-1}$ ( $\mathrm{C}=\mathrm{O}$ stretching vibration), and $1562.4 \mathrm{~cm}^{-1}$ (C-N stretching vibration and - $\mathrm{NH}$ bending vibration) in the IR spectroscopy of the profile control agent. The characteristic absorption at $1125.6 \mathrm{~cm}^{-1}$ and $848.9 \mathrm{~cm}^{-1}$ was assigned to in-plane C$\mathrm{H}$ bending vibration and out-plane $\mathrm{C}-\mathrm{H}$ bending vibration of resorcinol, respectively. The characteristic absorption at $615.8 \mathrm{~cm}^{-1}$ belonged to out-plane $\mathrm{N}-\mathrm{H}$ bending vibration of thiourea. As expected, the IR spectra demonstrated that PCAWDF was successfully synthesized.

3.3. Reaction Process and Profile Control Mechanism of PCAWDF. PCAWDF was mainly composed of HPAM, formaldehyde, resorcinol, and thiourea. Hydroxymethyl resorcinol was produced by condensation reaction between

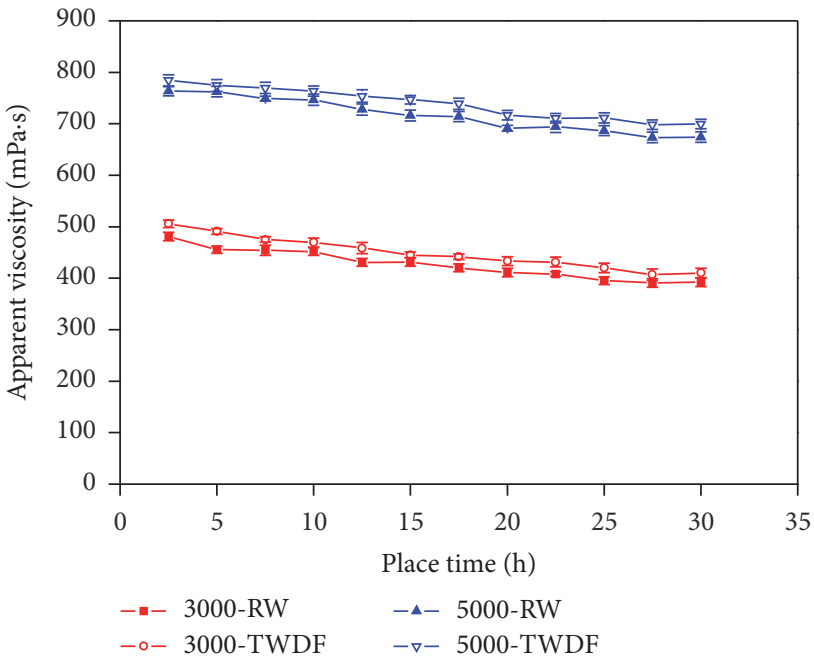

FIGURE 2: Effect of water quality on the viscosity of polymer solution with different concentration.

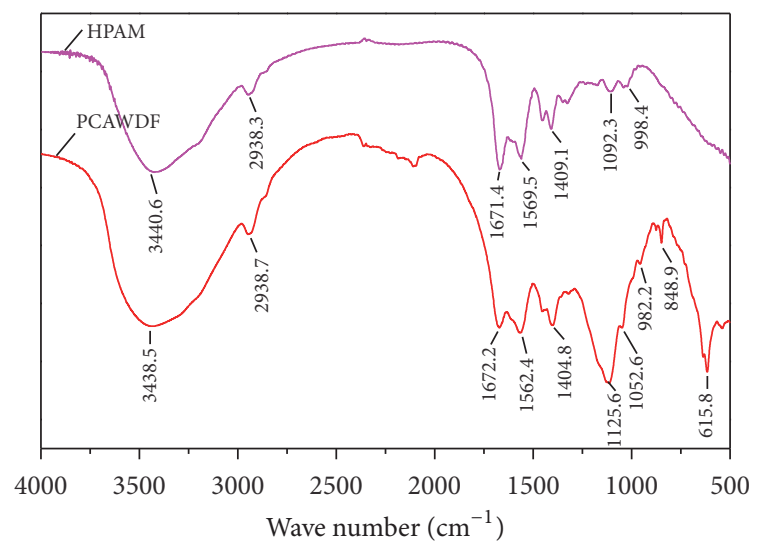

FIGURE 3: IR spectra of PCAWDF and HPAM.

formaldehyde and resorcinol. The methylol of hydroxymethyl resorcinol could react with the amino groups on HPAM. So PCAWDF had the complex spatial network structure. 


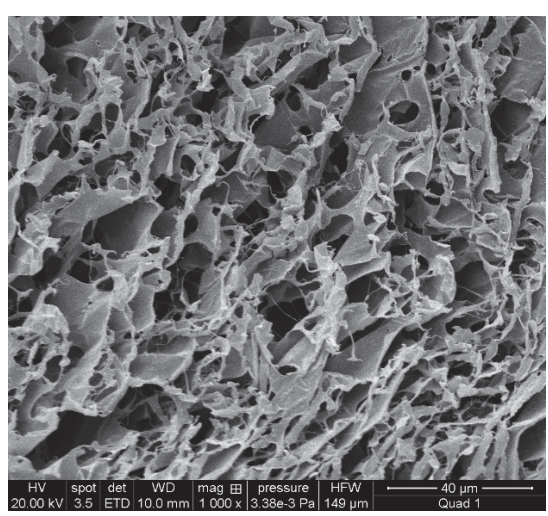

(a)

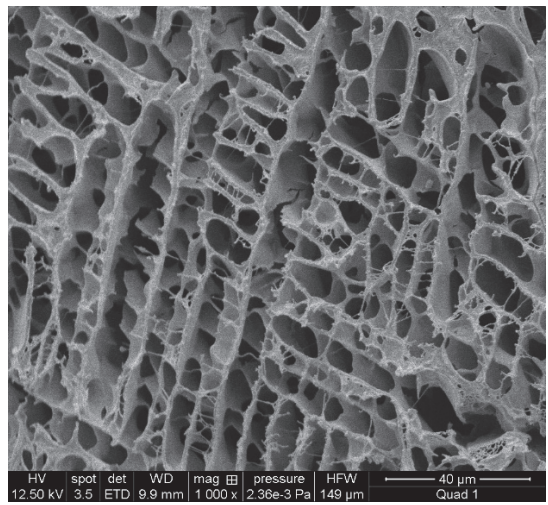

(d)

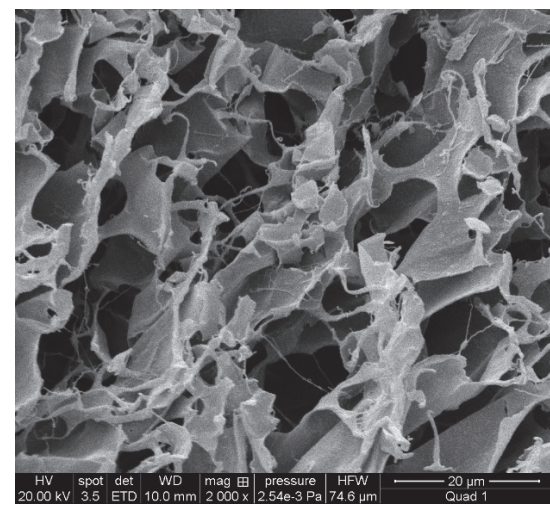

(b)

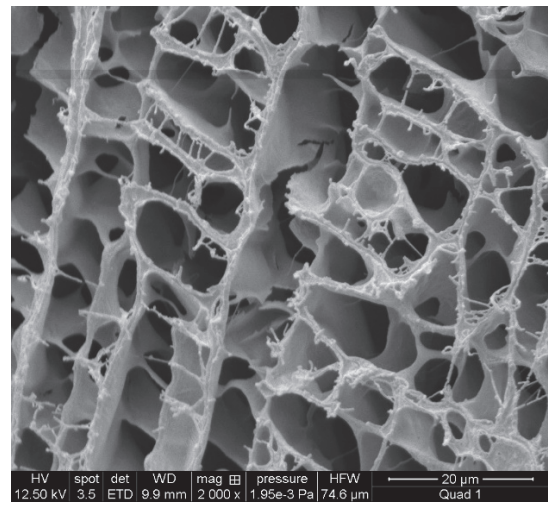

(e)

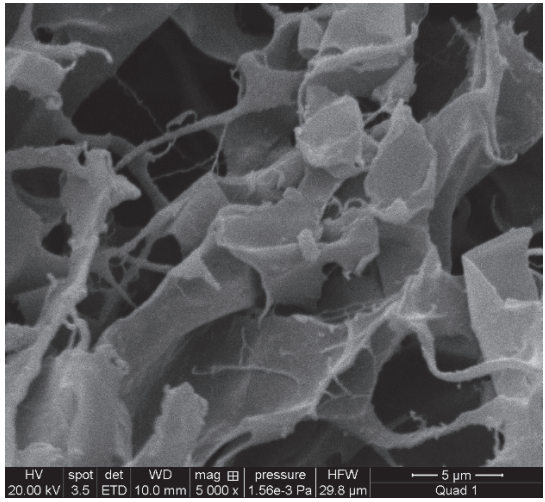

(c)

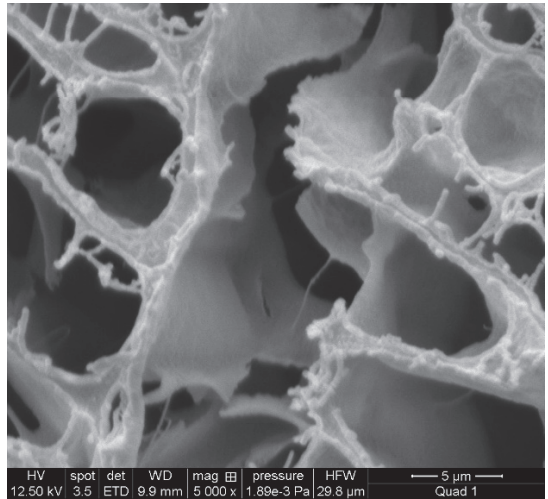

(f)

Figure 4: SEM images of PCARW and PCAWDF: (a) PCARW at $40 \mu \mathrm{m}, 1000 x$; (b) PCARW at $20 \mu \mathrm{m}, 2000 x$; (c) PCARW at $5 \mu \mathrm{m}, 5000 x$; (d) PCAWDF at $40 \mu \mathrm{m}, 1000 \mathrm{x}$; (e) PCAWDF at $20 \mu \mathrm{m}, 2000 \mathrm{x}$; (f) PCAWDF at 5 $\mu \mathrm{m}, 5000 \mathrm{x}$.

In the injection course, PCAWDF preferentially entered the high permeability zone, and it could form effective plugging for the high permeability zone. In the process of water injection, the injected water could only enter the low permeability zone, so the water absorption profile could be improved by PCAWDF.

3.4. Microscopic Structure Analysis by SEM. The microscopic structures of PCARW $(3000 \mathrm{mg} / \mathrm{L})$ and PCAWDF $(3000 \mathrm{mg} / \mathrm{L})$ were observed through SEM at room temperature. Among these images, Figures $4(\mathrm{a})-4(\mathrm{c})$ are PCARW at different scan sizes $(40 \mu \mathrm{m}, 1000 \mathrm{x} ; 20 \mu \mathrm{m}, 2000 \mathrm{x}$; and $5 \mu \mathrm{m}$, $5000 x$, resp.). Similarly, the images of PCAWDF are shown in Figure 4(d) $(40 \mu \mathrm{m}, 1000 \mathrm{x})$, Figure $4(\mathrm{e})(20 \mu \mathrm{m}, 2000 \mathrm{x})$, and Figure $4(\mathrm{f})(5 \mu \mathrm{m}, 5000 \mathrm{x})$. As shown in Figure 4 , it could be obviously observed that there were space net structures in the images of PCAWDF. Moreover, it could be found that the microscopic reticular structures of PCAWDF were much more compact than that of PCARW in the same scan size. The much denser spatial network structure of PCAWDF might be due to the effect of flocculant on water quality, because good water quality was conducive to the stretch of polymer molecular chain.
3.5. Strength of Profile Control Agents. The apparent viscosity versus place time curves of 3000-PCAWDF, 5000-PCAWDF, 3000-PCARW, and 5000-PCARW are shown in Figure 5. Glue time of both 3000-PCAWDF and 5000-PCAWDF was $15 \mathrm{~h}$. Strength of 3000-PCARW and 5000-PCARW was $35500 \mathrm{mPa} \cdot \mathrm{s}$ and $26100 \mathrm{mPa} \cdot \mathrm{s}$, respectively. Compared with 3000-PCARW and 5000-PCARW, 3000-PCAWDF and 5000PCAWDF displayed almost the same gel time and gel strength. This phenomenon proved once again the feasibility of replacing the recirculated water with TWDF.

3.6. Stability. The apparent viscosity versus temperature curves of profile control agents are shown in Figure 6. At $65^{\circ} \mathrm{C}, 3000$-PCAWDF and 3000-PCARW had the same good stability. After 180 days, the apparent viscosity of 3000 -PCAWDF was decreased by only $10 \%$ at $65^{\circ} \mathrm{C}$. The experimental results showed that the flocculant and $\mathrm{pH}$ modifier could reduce the influence of additives in the waste drilling fluid on the polymer chain. Two valence cations (such as calcium ion, magnesium ion) concentration decreased significantly in the role of flocculant, and polymers were more conducive to maintaining the integrity of molecular chains under neutral conditions. The polymer molecular chain could 


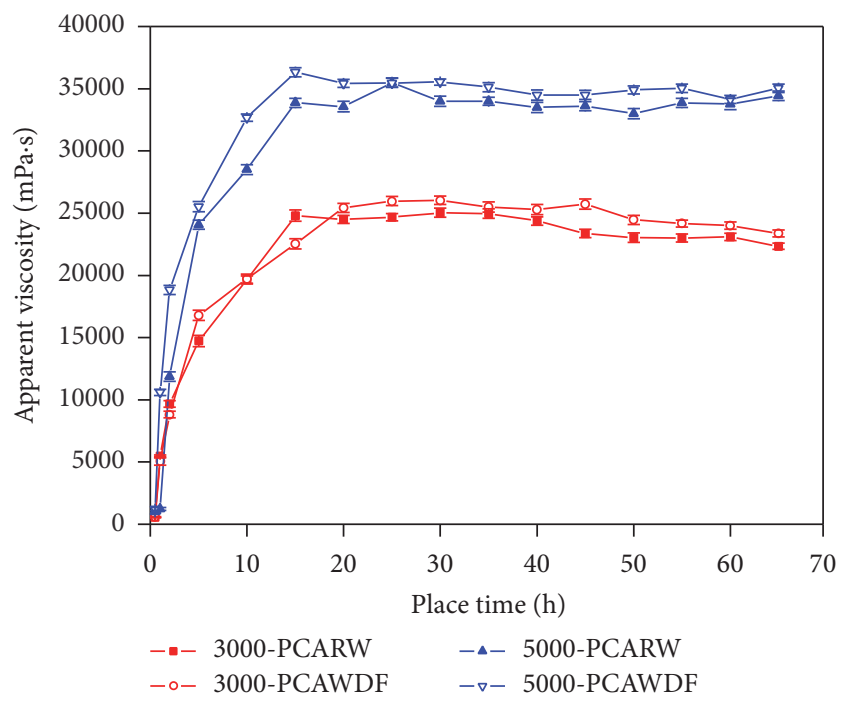

Figure 5: The apparent viscosity versus place time curves.

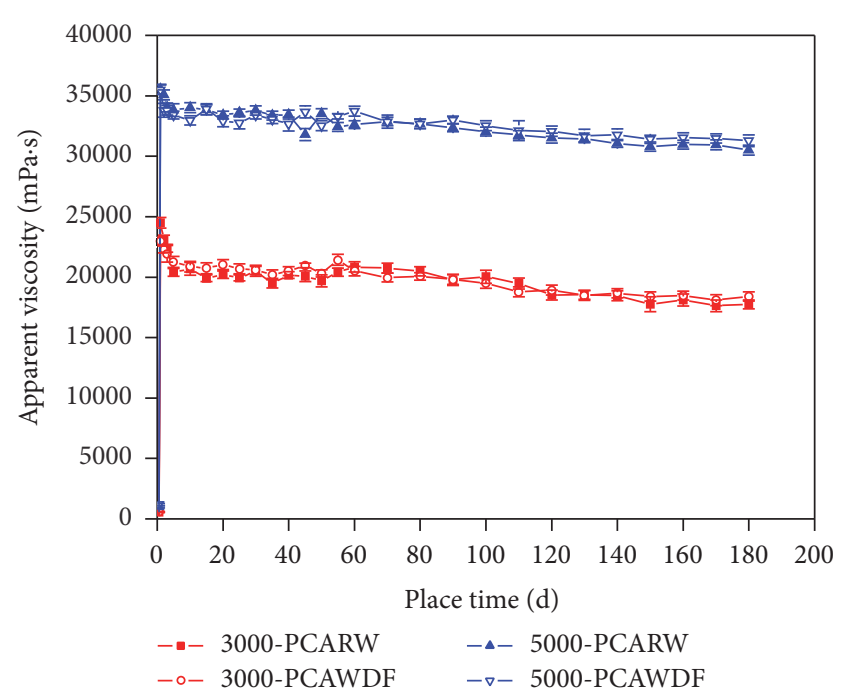

FIGURE 6: Apparent viscosity versus temperature curves of profile control agents.

be stable for a long time at $65^{\circ} \mathrm{C}$, so 3000 -PCAWDF and 5000PCAWDF showed satisfactory stability. This performance might ensure the validity of profile control to a certain extent.

3.7. Salt Resistance. The influences of $\mathrm{NaCl}$ on apparent viscosity of these profile control agents were carried out at $65^{\circ} \mathrm{C}$. As shown in Figure 7, with the increase of $\mathrm{NaCl}$ concentration, the apparent viscosity of 3000-PCAWDF and 5000-PCAWDF decreased rapidly, and then it kept at a low value. Similarly, the measurement results of 3000-PCARW and 5000-PCARW displayed similar phenomena. However, compared with 3000-PCARW, 3000-PCAWDF displayed better antisalt under the same conditions. This phenomenon could be well explained by a more compact space mesh structure, which could reduce the effect of salt on the polymer molecules. The stronger the network structure, the stronger

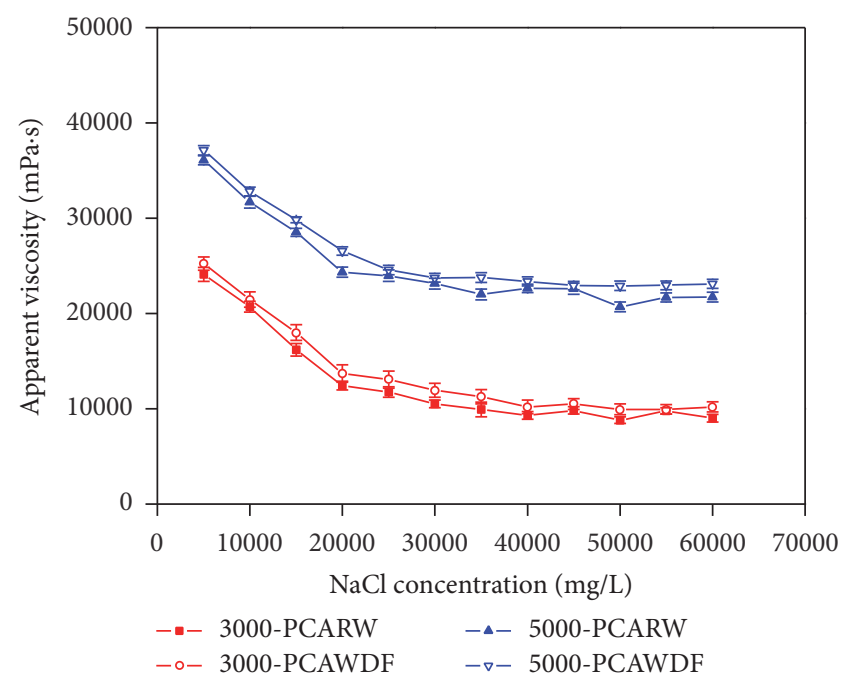

Figure 7: Apparent viscosity versus $\mathrm{NaCl}$ concentration curves at $65^{\circ} \mathrm{C}$.

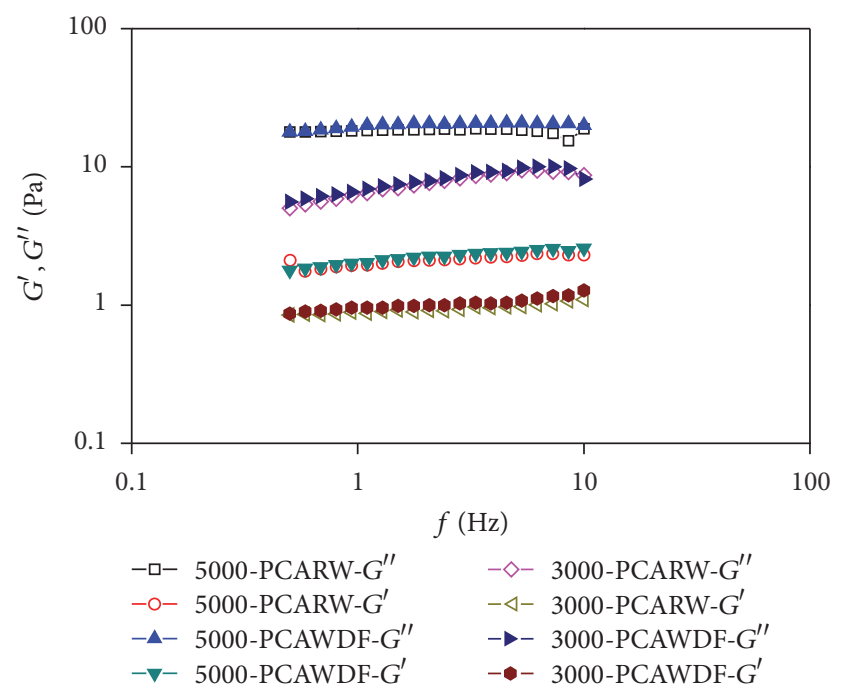

FIGURE 8: The viscosity modulus and elastic modulus versus scanning frequency curves of the profile control agents.

the interaction between the molecular chains. Under the same concentration of salt, the molecular chain curled degree was smaller. So the apparent viscosity of 3000-PCAWDF was higher than that of 3000-PCARW in the same $\mathrm{NaCl}$ concentration.

3.8. Viscoelasticity. The viscosity modulus $\left(G^{\prime \prime}\right)$ and elastic modulus $\left(G^{\prime}\right)$ versus scanning frequency curves of these profile control agents are shown in Figure 8. The experimental results showed that the elastic modulus of 3000-PCAWDF was larger than that of the viscosity modulus in the whole scanning frequency range. In the linear scan range, the viscosity modulus and elastic modulus of 3000-PCAWDF were slightly higher than those of 3000-PCARW. And mass concentration of $5000 \mathrm{mg} / \mathrm{L}$ profile control agents showed the same regularity. This phenomenon might be explained by the 
TABLE 3: The parameters and results of the core experiments.

\begin{tabular}{|c|c|c|c|c|c|c|}
\hline $\begin{array}{l}\text { Profile control } \\
\text { agents }\end{array}$ & $\begin{array}{l}\text { Sand } \\
\text { filling } \\
\text { model }\end{array}$ & $\begin{array}{l}\text { Porosity } \\
(\%)\end{array}$ & $\begin{array}{l}\text { Permeability before } \\
\text { profile control (D) }\end{array}$ & $\begin{array}{l}\text { Percentage of water } \\
\text { absorption before } \\
\text { profile control (\%) }\end{array}$ & $\begin{array}{l}\text { Percentage of water } \\
\text { absorption after } \\
\text { profile control (\%) }\end{array}$ & $\begin{array}{c}\text { Profile } \\
\text { improvement rate } \\
(\%)\end{array}$ \\
\hline \multirow{2}{*}{ 3000-PCAWDF } & $1 \#$ & 35.9 & 5.83 & 88 & 53 & \multirow{2}{*}{84.6} \\
\hline & $2 \#$ & 30.5 & 1.05 & 12 & 47 & \\
\hline \multirow{2}{*}{ 3000-PCARW } & $3 \#$ & 35.3 & 5.62 & 86 & 51 & \multirow{2}{*}{83.1} \\
\hline & $4 \#$ & 30.7 & 1.15 & 14 & 49 & \\
\hline \multirow{2}{*}{ 5000-PCAWDF } & $5 \#$ & 35.8 & 5.74 & 89 & 40 & \multirow{2}{*}{91.8} \\
\hline & $6 \#$ & 30.4 & 1.07 & 11 & 60 & \\
\hline \multirow{2}{*}{ 5000-PCARW } & 7\# & 35.1 & 5.58 & 84 & 34 & \multirow{2}{*}{90.2} \\
\hline & 8\# & 30.1 & 1.02 & 16 & 66 & \\
\hline
\end{tabular}

space mesh structures of 3000-PCAWDF more closely than that of 3000-PCARW. The stronger the interaction between the molecular chains, the lower the degree of deformation of the molecular chain in the external force. So, in the same conditions, 3000-PCAWDF had a stronger flexibility.

3.9. Profile Improvement Rate. The parameters and results of the core experiments are shown in Table 3. Profile improvement rate of profile control agent was related to its concentration. The higher the concentration of profile control agent, the higher the profile improvement rate under the same experimental conditions. Compared with 3000PCARW, 3000-PCAWDF displayed better profile improvement rate $(84.6 \%$ versus $83.1 \%)$. This was because 3000 PCAWDF had a higher apparent viscosity and viscoelasticity, which were conducive to enhancing its sealing performance. In addition, compared with 3000-PCARW, due to the strong interaction between the molecular chains of 3000-PCAWDF, the shear failure in the injection process was small, and the gel strength of 3000-PCAWDF was higher after being injected in the core.

\section{Conclusions}

A novel profile control agent base on waste drilling fluid was successfully prepared using polymer, formaldehyde, resorcinol, and thiourea as raw materials under mild conditions. Compared with the profile control agent prepared by the recirculated water, PCAWDF exhibited comparable or better stability, salt resistance, viscoelasticity, and profile improvement rate due to the introduction of the flocculant and $\mathrm{pH}$ modifier. In addition, the crosslinking agent system had good compatibility with the polymer. This not only provided a new method for safe and environmentally friendly disposal of waste drilling fluid, but also helped to improve the effect of profile control for the water injection wells.

\section{Conflicts of Interest}

The authors declare no possible conflicts of interest.

\section{Acknowledgments}

This work was supported by the major project of Jidong Oilfield (ZC2015B01-02) and the projects of China National Petroleum Corporation (2014B-1113, KT2015-16-06).

\section{References}

[1] T. L. Chen, S. Lin, G. V. Chilingar, and Z.-S. Lin, “The reutilization of drilling fluid wastes as material for the manufacture of bricks," Energy Sources, Part A: Recovery, Utilization and Environmental Effects, vol. 32, no. 15, pp. 1399-1407, 2010.

[2] M. E. Hossain and M. Wajheeuddin, "The use of grass as an environmentally friendly additive in water-based drilling fluids," Petroleum Science, vol. 13, no. 2, pp. 292-303, 2016.

[3] S. M. Almudhhi, "Environmental impact of disposal of oilbased mud waste in Kuwait," Petroleum Science and Technology, vol. 34, no. 1, pp. 91-96, 2016.

[4] J. Zou, H. Zhu, F. Wang, H. Sui, and J. Fan, "Preparation of a new inorganic-organic composite flocculant used in solid-liquid separation for waste drilling fluid," Chemical Engineering Journal, vol. 171, no. 1, pp. 350-356, 2011.

[5] M. A. Sayyadnejad, H. R. Ghaffarian, and M. Saeidi, "Removal of hydrogen sulfide by zinc oxide nanoparticles in drilling fluid," International Journal of Environmental Science and Technology, vol. 5, no. 4, pp. 565-569, 2008.

[6] M. O. Benka-Coker and A. Olumagin, "Effects of waste drilling fluid on bacterial isolates from a mangrove swamp oilfield location in the Niger Delta of Nigeria," Bioresource Technology, vol. 55, no. 3, pp. 175-179, 1996.

[7] L. Ren, G. Zhao, T. Qiang, X. Wang, and X. Zhang, "Study on the application of cationic collagen copolymer in waste drilling fluid," Speciality Petrochemicals, vol. 30, no. 3, pp. 27-31, 2013.

[8] T. A. Bauder, K. A. Barbarick, J. F. Shanahan, P. D. Ayers, and P. L. Chapman, "Drilling fluid effects on crop growth and iron and zinc availability," Journal of Environmental Quality, vol. 28, no. 3, pp. 744-749, 1999.

[9] R. B. Brobst and P. M. Buszka, "The effect of three drilling fluids on ground water sample chemistry," Groundwater Monitoring \& Remediation, vol. 6, no. 1, pp. 62-70, 1986. 
[10] X. Wang, S. Zhang, L. Zhou, and L. Ren, "The hydrolysis of gelatin and its treatment for waste drilling fluid," Advanced Materials Research, vol. 281, pp. 141-146, 2011.

[11] D. Denney, "Holistic drilling-fluid and waste management in the fayetteville shale," Journal of Petroleum Technology, vol. 63, no. 11, pp. 68-70, 2011.

[12] B. Hou, C. Liang, H. Deng, S. Xie, M. Chen, and R. Wang, "Oil removing technology of residues from waste oil-based drilling fluid treated by solid-liquid separation," Journal of Residuals Science and Technology, vol. 9, no. 4, pp. 143-150, 2012.

[13] S. X. Xie, G. C. Jiang, M. Chen et al., "Treatment technology for waste drilling fluids in environmental sensitivity areas," Energy Sources, Part A: Recovery, Utilization and Environmental Effects, vol. 37, no. 8, pp. 817-824, 2015.

[14] C. Zou, M. Liang, X. Chen, and X. Yan, " $\beta$-Cyclodextrin modified cationic acrylamide polymers for flocculating waste drilling fluids," Journal of Applied Polymer Science, vol. 131, no. 9, pp. 93-98, 2014.

[15] S. X. Xie, G. C. Jiang, M. Chen et al., "Harmless treatment technology of waste oil-based drilling fluids," Petroleum Science and Technology, vol. 32, no. 9, pp. 1043-1049, 2014.

[16] J. S. Adeyinka, U. R. Iselema, and M. K. Oghenojoboh, "Effect of drilling fluid waste disposal on Owaza region of the Niger delta: an assessment of nitrate and sulphate ions on base metal leaching," Journal of Scientific and Industrial Research, vol. 63, no. 2, pp. 134-141, 2004.

[17] B. Hou, M. Chen, M. Liu, and Q. Xiong, "Safe disposal technology of waste oil-based drilling fluids," Journal of the Japan Petroleum Institute, vol. 56, no. 4, pp. 221-229, 2013.

[18] G. Jiang, S. Xie, M. Chen et al., "Oil dispersant preparation and mechanisms for waste oil-based drilling fluids," Environmental Progress and Sustainable Energy, vol. 31, no. 4, pp. 507-514, 2012. 

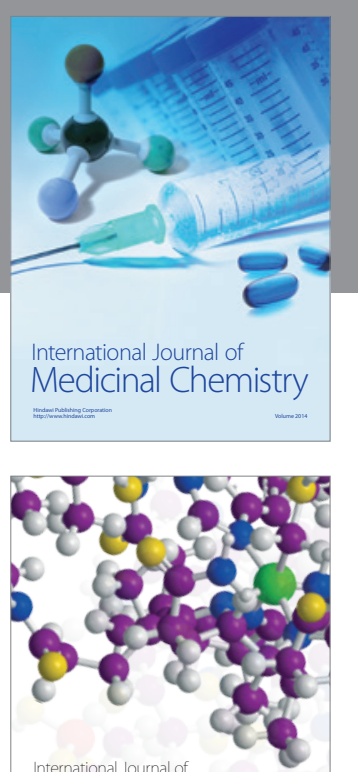

Carbohydrate Chemistry

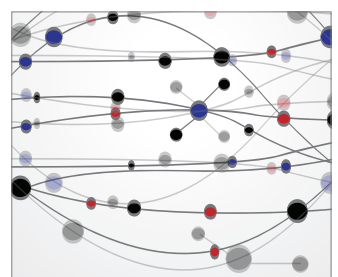

The Scientific World Journal
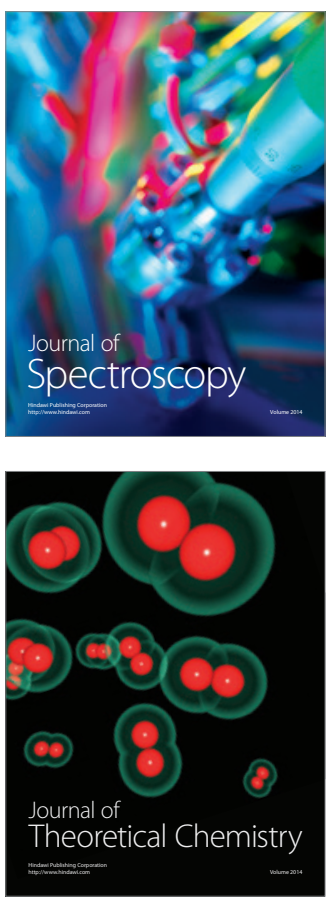
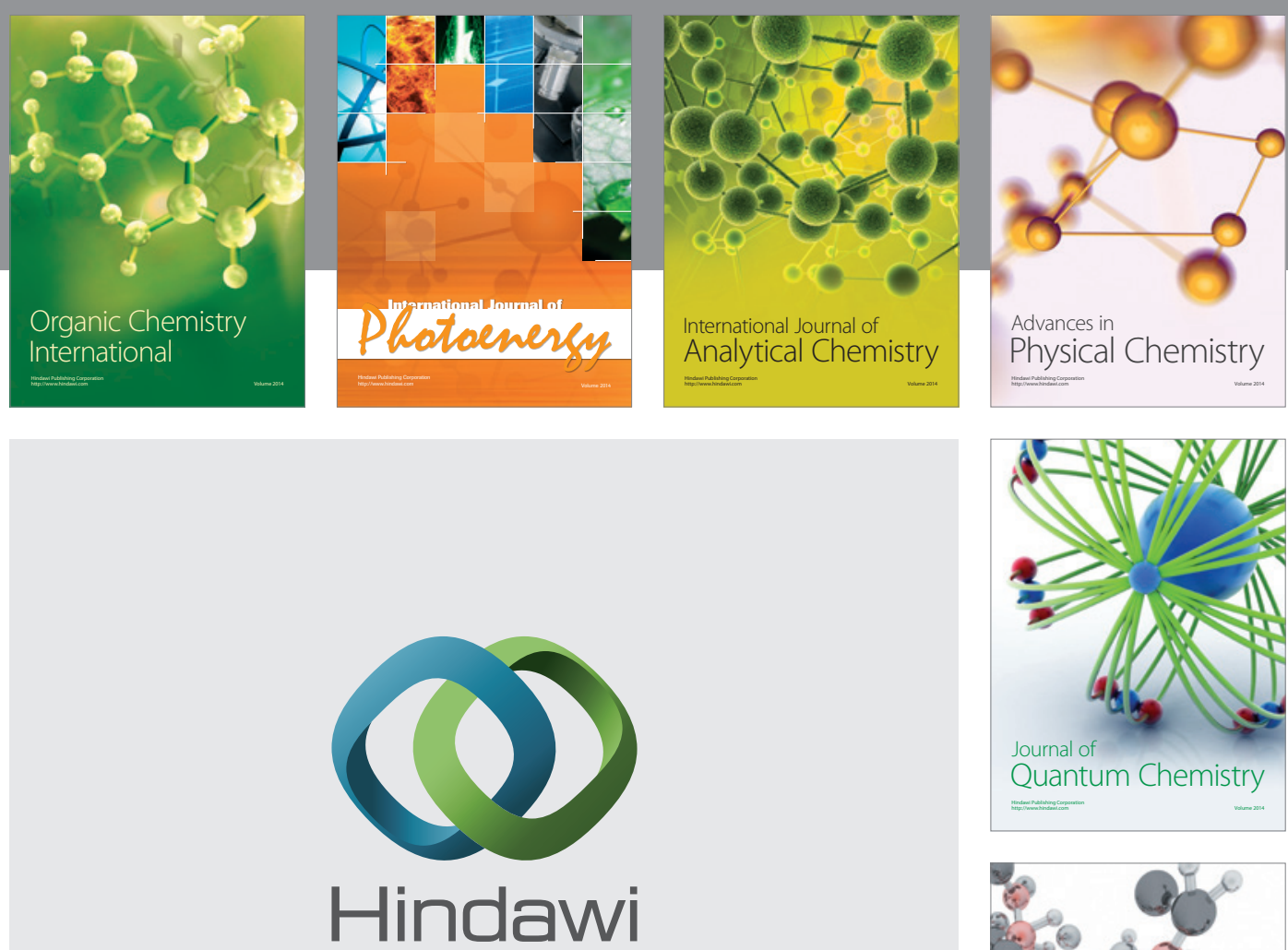

Submit your manuscripts at

https://www.hindawi.com

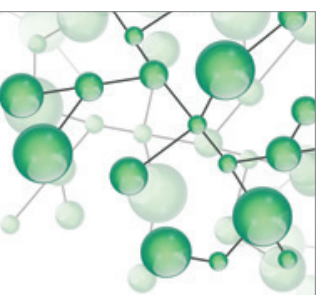

International Journal of

Inorganic Chemistry
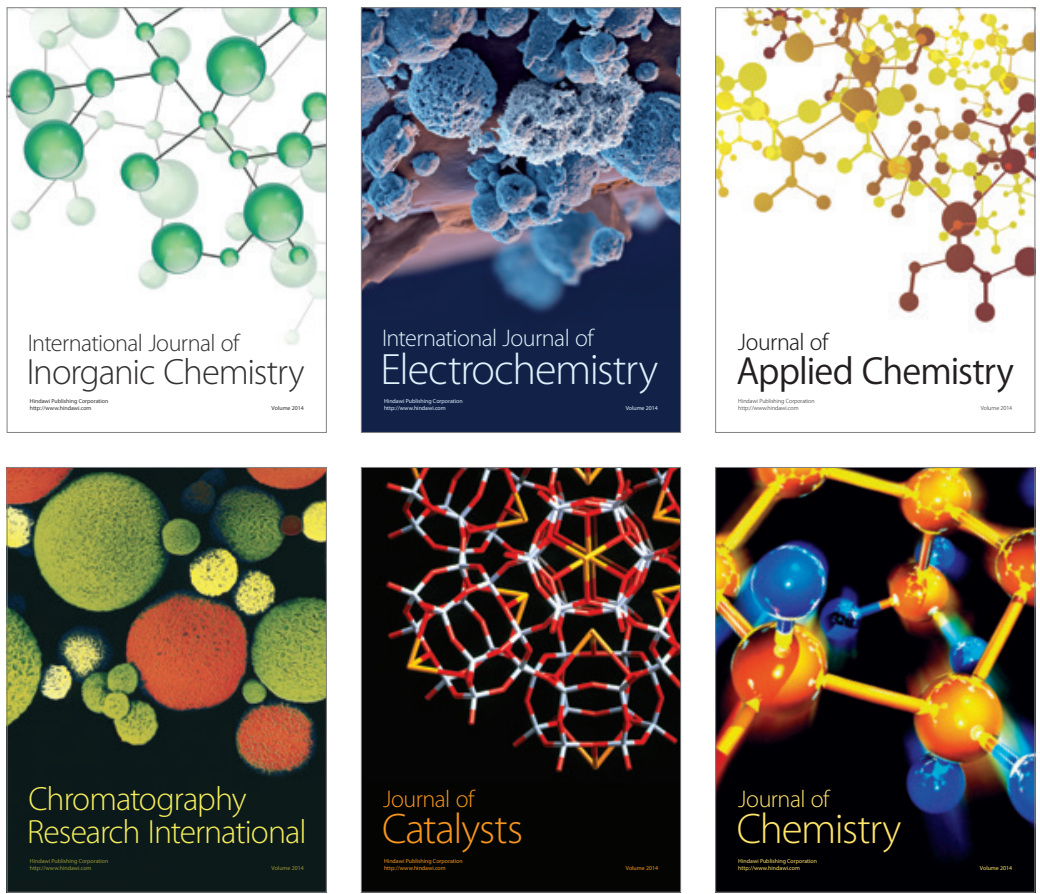

Journal of

Applied Chemistry
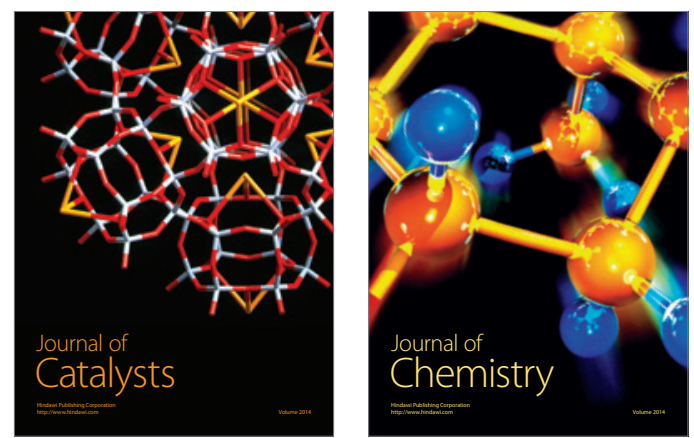
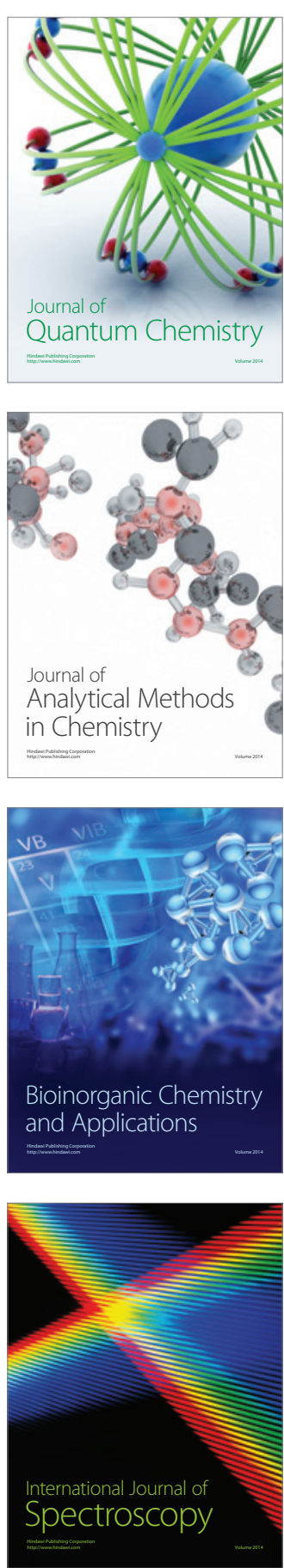